\section{Elective on PTSD and mental health in Gulu, northern Uganda, December 2008-January 2009}

C. I chose a psychiatry elective because of my - interest in Uganda. There is a high rate of posttraumatic stress disorder (PTSD) among the Acholi people in the north, following the 1986-2006 guerrilla war between the Ugandan government and the rebel Lord's Resistance Army (LRA).

The LRA is infamous for using child soldiers (during the conflict, 30000-60000 children were abducted, making up over $90 \%$ of LRA troops) and committing atrocities against civilians. Villages were attacked, their inhabitants killed, beaten and raped; crops and stores were stolen and roads made impassable. In an attempt to gain control, the Ugandan government moved over $90 \%$ of the population of the north into camps for internally displaced persons; by 2005 these contained 2 million people. Unable to farm, the Acholi became dependent on the World Food Programme.

PTSD is found both in former child soldiers and civilian victims. Gulu town, once at the centre of the conflict, is now at the heart of regeneration. I worked with three organisations there:

O Gulu Regional Referral Hospital Mental Health Unit, the main psychiatric centre in the north, which runs outreach and daily out-patient clinics

o The Peter C. Alderman Foundation, an American nongovernmental organisation (NGO) which specialises in rehabilitating victims of trauma, and which works closely with Gulu Hospital

$O$ the African Centre for Treatment and Rehabilitation of Trauma Victims (ACTV), staff from which spend up to 4 days at a time in the field addressing all aspects of victims' lives.

Psychiatry is very paternalistic in Uganda, but PTSD management seems an exception, focusing on talking therapies, involving the patient in treatment. Medication is used in most cases, primarily antidepressants (usually amitriptyline), often with an antipsychotic (haloperidol). Almost universally, patients I spoke to had seen a benefit from therapy, especially meeting others who shared their experiences. But the further people are from Gulu town, the harder it is for them to access help.

The ACTV works effectively using a multidisciplinary approach. It has discussions led by social workers and drama projects which recall and deal with the trauma of the past. A clinical officer manages medication and a staff physiotherapist deals with stress-related musculoskeletal pain. Lawyers and social workers offer advice on everything from domestic violence to the land wrangles which resulted when families returned from camps to find strangers occupying their land. All aspects of patients' problems are covered.

Although there were fewer hands-on opportunities for me than there might have been in a medical elective, all the teams involved me fully. I found my psychiatry elective an excellent way to develop the brief grounding I had as a student - and by visiting a low-income country I learned a way of practising using limited resources. The 'Western' way of treating patients simply is not possible (for instance following guidelines produced by the National Institute for Health and Clinical Excellence).
A place as traumatised as northern Uganda will not heal overnight; but hope remains as long as victims of trauma have someone to talk to - even though, as one ACTV social worker told me - 'sometimes the best you can do is listen to their stories and say "I'm sorry"'.

Emily Sherley

Student Associate of the RCPsych

\section{'Legal highs' - a health warning that does not appear on the wrapper}

C. There are an increasing number of substances - appearing on the recreational drug scenes in Europe, North America, Oceania and Japan (International Narcotics Control Board, 2011). In 2009 for example, 24 new psychoactive substances were notified in Europe, compared with 13 in 2008, including synthetic cannabinoids, tryptamines, phenethylamines and synthetic cathinones, according to the European Monitoring Centre for Drugs and Drug Addiction (EMCDDA \& Europol, 2009).

Many are synthesised by chemists who modify the structure of existing psychoactive substances controlled by United Nations conventions so that they remain legal. These new generations of 'designer drugs' are marketed as 'legal highs', and sold in 'head shops' and increasingly over the internet as 'research chemicals'. Purity levels are very high; they are laboratory manufactured and sold, for example, as 'synthetic cocaine'. Thus, the products appear to potential consumers as both legal and safe.

Such assumptions are dangerous. If sold under a 'brand name', the contents and active ingredients are not listed; consumers do not know what they are taking. Even if a substance is advertised using its chemical name, is extremely pure and is chemically related to drugs with known desired psychoactive properties, there is no guarantee that it does not have potential adverse or even toxic effects. Adverse effects reported by users in recent years include psychiatric conditions such as psychoses, depression, anxiety, paranoia and suicidal ideation. Physiological effects similar to those experienced by overdosing on amphetamines, cocaine and ecstasy have been reported by attendees at emergency departments. Sometimes, these complications have resulted in fatalities (Ghodse et al, 2010).

Such occurrences led to risk assessments being conducted at national level in many countries, resulting in substances being controlled. For example, the Council of Europe on 2 December 2010, following a formal risk assessment (EMCDDA, 2010), adopted a Decision submitting mephedrone to control measures (Council of Europe, 2010). Following new controls, some chemists further manipulated the molecules of these chemicals so that they complied with the law.

New psychoactive substances are appearing at an increasingly faster rate than hitherto. Users are exposed to all types of unknown risks, as research and analyses have not been undertaken. Branded products may contain different active ingredients than when first marketed. For instance, initially, 
'Ivory Wave' contained mephedrone, methylenedioxypyrovalerone (MDPV) and other cathinones but, following their control, desoxypipradrol was substituted. Imports of this latter chemical were restricted, but retailers released older stocks containing MDPV.

One beneficial effect of the control of mephedrone in the UK and media coverage of the adverse mental and physical properties of the substance was a fall in the number of suspected and confirmed fatalities involving its use.

Health professionals should be aware of the ever-changing nature of recreational drug use and the potential mental and physical health problems that may be caused by the consumption of new psychoactive molecules. Patients should be asked about their use of 'legal highs', as well as other substances misused.

John M. Corkery

Senior Research Fellow in Drug Epidemiology, International Centre for Drug Policy, St George's, University of London, email jcorkery@sgul.ac.uk
Council of Europe (2010) Council Decision 2010/759/EU on submitting 4-methylmethcathinone (mephedrone) to control measures. Available at http://www.emcdda.europa.eu/attachements.cfm/att 121058 EN Council_Decision_2010_759_EU_2_December_2010.pdf (accessed March 2011).

EMCDDA (2010) Risk-assessment report of a new psychoactive substance: 4-methylmethcathinone (mephedrone). European Monitoring Centre for Drugs and Drug Addiction. Available at http://www.emcdda. europa.eu/attachements.cfm/att_116485_EN_Risk\%20Assessment\%2 OReport\%20on\%20mephedrone.pdf (accessed March 2011).

EMCDDA \& Europol (2009) EMCDDA-Europol 2009 Annual Report on the Implementation of Council Decision 2005/387/JHA - In Accordance with Article 10 of Council Decision 2005/387/JHA on the Information Exchange, Risk-Assessment and Control of New Psychoactive Substances. European Monitoring Centre for Drugs and Drug Addiction Available at http://www.emcdda.europa.eu/ attachements.cfm/att_101536_EN_EMCDDA-Europol\%20Annual\%20 Report\%202009_EDOC\%20458303-1.pdf (accessed March 2011).

Ghodse, H., Corkery, J., Ahmed, K., et al (2010) Drug-Related Deaths in the UK: Annual Report 2010. International Centre for Drug Policy, St George's, University of London. Available at http://www.sgul.ac.uk/ research/projects/icdp/pdf/np-sad-11 th-annual-report-2010-finalcopy. pdf (accessed March 2011).

International Narcotics Control Board (2011) Report of the International Narcotics Control Board for 2010 (E/INCB/2010/1). INCB. Available at http://www.incb.org/pdf/annual-report/2010/en/AR_2010_English.pdf (accessed March 2011).

\section{International Congress of the Royal College of Psychiatrists 28 June - 1 July 2011, Hilton Metropole, Brighton, UK}

Forensic

Developing services

Neurology

Neurocognitive Interface

\author{
New science \\ Mood disorders \\ Clinical skills \\ Care pathways \\ Management
}

\author{
Treatment resistant psychosis \\ Psychopharmacology \\ Personality disorders \\ Teaching and training \\ Trainees
}

Accreditation: This congress is accredited for up to 24 CPD and EACCME credits. EACCME credits are recognized by the American Medical Association towards the Physician's Recognition Award (PRA).

Brighton is just 30 minutes by road or rail from London Gatwick Airport and just under 1 hour away from London.

For further information please contact:

$\mathrm{T}:+442072352351 \times 6129$

E: conference@rcpsych.ac.uk

w: http://www.rcpsych.ac.uk/events/internationalcongress2011.aspx

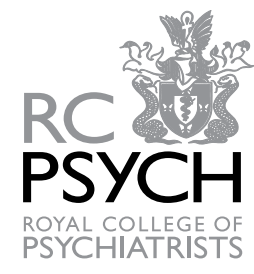

